\title{
FMS Squat Assessment and 2D Video Motion Analysis as Screening Indicators of Low Back Pain: A Cross Sectional Case- Study
}

\author{
Donlon, T., Franklin, B., Machamer, C., Mogelnicki, C., Verneus, J., and Taber, C.B.
}

\begin{abstract}
Aim: Low back pain (LBP) is a disabling condition to individuals in the United States and physical therapy (PT) has been proven to be a beneficial treatment by analyzing their movement patterns. The main objective of this study was to analyze the deep squat component of the Functional Movement Screen (FMS) as an indicator of LBP while simultaneously using 2-D analysis. Method: This cross-sectional case study included 36 participants that completed a total of six deep squats. Three raters scored the FMS score of each participant. Results: The association between FMS score and the presence of LBP showed to be insignificant $(\mathrm{p}=0.119)$. Knee joint angles with 2-D analysis demonstrated a moderate correlation $(\rho=0.520)$ to those with LBP, as well as knee joint angles on the ground $(\rho=0.461)$. Conclusion: This study concluded that the FMS deep squat assessment was not a objective indicator of patients with LBP whereas 2-D motion capture was an objective measure.
\end{abstract}

\section{Donlon Tracy}

Third year Physical Therapy Student in

the Doctorate of Physical Therapy, Department of Physical Therapy \&

Human Movement Science, Sacred Heart University

Email: donlont@mail.sacredheart.edu

Franklin, Brittany

Third year Physical Therapy Student in

the Doctorate of Physical Therapy, Department of Physical Therapy \&

Human Movement Science, Sacred Heart University

Email: franklinb6@sacredheart.edu

Machamer, Courtney

Third year Physical Therapy Student in

the Doctorate of Physical Therapy, Department of Physical Therapy \&

Human Movement Science, Sacred Heart University

Email: machamerc@ sacredheart.edu

Mogelnicki, Christina

Third year Physical Therapy Student in

the Doctorate of Physical Therapy, Department of Physical Therapy \&

Human Movement Science, Sacred Heart University

Email: mogelnickic@sacredheart.edu

Verneus, Jeffrey

Third year Physical Therapy Student in

the Doctorate of Physical Therapy, Department of Physical Therapy \&

Human Movement Science, Sacred Heart University

Email: verneusj@sacredheart.edu

Taber, Christopher B

Assistant Professor

Department of Physical Therapy \& Human Movement Science

Sacred Heart University

Email: Taberc@sacredheart.edu.

\section{Introduction}

Low back pain (LBP) is a prevalent and disabling condition creating personal and financial burdens on patients (Hoy et al., 2012). Low back pain is further classified as discomfort below the twelfth
Key Words: Low back pain, Assessment, Squat, Functional Movement Screen, Kinovea Motion Analysis

DOI: $10.18376 / j e s p / 2018 / v 14 / i 2 / 111300$ 


\section{Journal of Exercise Science \& Physiotherapy Vol. 14 No. 2 (July to December) 2018 ISSN: 0973-2020 (Print) $\quad I_{2}$ OR Impact Factor =6.115 UGC Approved [no.7485] ISSN: 2454-6089 (Online)}

rib and above the inferior gluteal fold (Meucci et al., 2013). Low back pain has been shown to affect over $50 \%$ of the population in the United States with national referral rates to physical therapy estimating between 7-20\% (Ahmed et al., 2017; Gore et al, 2012). Patients with LBP tend to experience physical and psychosocial deficits, as well as large economic burden due to lost work productivity (Ahmed et al., 2017; Childs et al., 2015; Gore et al., 2012). This in turn decreases the quality of life for those with LBP. When considering the economic burden of LBP, it should be considered by all stakeholders, including patients, clinicians, and third-party payers when deciding on the allocation of healthcare resources (Dagenais et al., 2008). Direct medical costs for LBP commonly include costs incurred for physician services, medical devices, medications, hospital services, diagnostic testing, etc. (Dagenais et al., 2008). In some cases, LBP will be treated with surgery or percutaneous procedures (Chenot et al., 2017). Low back pain can also be treated with non-pharmacological treatments including physical therapy or exercise therapy utilizing behavioraltherapeutic principles (Chenot et al., 2017). Pharmacologically, LBP is widely treated with the use of opioids if the physician considered it helpful in the acute phase. Opioids are also commonly used when the patient has an intolerable functional impairment because of their pain in the chronic stage (pain persisting > $3 \mathrm{mo}$ ) (Chenot et al., 2017). Opioids are among the most commonly prescribed medications in the United States (Chu 2012). Opioids have limited long-term benefits and present issues with tolerability causing an association of misuse and abuse (Gore et al., 2012). Physical therapy has been recommended as a beneficial conservative treatment for LBP in which patients can experience significant improvements (Zheng et al., 2017). In a study conducted by Frogner et al. (2018), 150,000 insurance claims were assessed to support the use of physical therapy services in patients with low back pain. The study revealed that the patients who saw a physical therapist at the first point of care had an $89 \%$ lower rate of opioid prescription, $28 \%$ lower probability of needing advanced imaging services, and $15 \%$ lower rate of an emergency department visit (Frogner et al., 2018). Low back pain has been said to be multifactorial with causes including, but not limited to, individual characteristics, occupation, and psychosocial factors. The treatment of LBP is complicated due to the difficulty of identifying the mechanisms of pain. About $85 \%$ of all cases of low back pain are classified as non-specific and without known origin. Many of the treatments delivered by physical therapist can be ineffective if the largest contributing factor to the patient's pain is not identified (Searle et al, 2015). In order to target exercises appropriately to the patient's condition, physical therapists need to find an effective way of assessing movement and looking for errors in body mechanics. Movement faults, are an abnormal way the body moves which puts increased stress on the musculoskeletal system. The increased stress may be from a small movement error, but when added up through the day can have a large effect on the body and lead to subsequent pain. By focusing on movement faults and correcting poor mechanics, physical therapists can play a significant role in treating patients with LBP pathologies. The evaluation of movement patterns is important to address poor underlying mechanics leading to potential injuries (Dorrel et al., 2018). The gold standard for identification of movement faults is through use of three-dimensional (3D) video analysis (Schurr et al., 2017). Three-dimensional analysis captures movement in the frontal, sagittal, and transverse planes simultaneously, providing researchers with a more comprehensive understanding of the movement fault (Schurr et al., 2017). Threedimensional analysis is both expensive and time consuming and not commonly part of the clinical setting. For that reason, two-dimensional (2D) analysis is most often used to capture movement faults (Schurr et al., 2017). It has been found that when evaluating sagittal plane joint displacements, 2D analysis is just as reliable as 3D analysis and can be used to screen for movement faults and decrease the risk of injury (Schurr et al., 2017). Being able to identify and address the cause of faulty movements facilitates optimal and safe performance of fundamental movements that occur every day (Dorrel et al., 2018). The squat is a key movement of many 


\section{Journal of Exercise Science \& Physiotherapy Vol. 14 No. 2 (July to December) 2018 \\ ISSN: 0973-2020 (Print) $\quad I_{2}$ OR Impact Factor $=6.115$ UGC Approved [no.7485] ISSN: 2454-6089 (Online)}

athletic activities, requiring both mobility and stability of the ankle, knee, hip and spine, as well as coordination and strength through the entire kinetic chain (Butler et al., 2010; Krause et al., 2015). Additionally, a person's squat mechanics also translates into many everyday activities such as lifting and lowering objects, sit to stand transfers and activities such as gardening (Myer et al., 2014). Movement faults can be due to weakness, poor form, decreased stability and/or limited mobility which can be caused by mechanical problems, range of motion deficits, and/ or muscle weakness. These movement faults can lead to LBP and a decrease in the quality of life (Butler et al., 2010; Myer et al., 2014).

The Functional Movement Screen (FMS) is an injury-screening tool that was developed to assess and measure essential movement patterns in a practical and dynamic way (Dorrel et al., 2018; Butler et al., 2010). This tool is used to identify asymmetries in functional movement and predict those who are at risk for injuries (Shultz et al., 2013). The FMS is a reliable screening tool for establishing a baseline of movement for comparisons after performance training, treatment, and rehabilitation (Dorrel et al., 2018). This screen consists of seven components: the deep squat, hurdle step, inline lunge, active straight leg raise, trunk stability push-up, rotary stability and shoulder mobility tests. The FMS can be scored as separate components which are scored on a scale of 0-3, or can be scored as a composite of the subsets in which the entire battery of tests are scored on a scale from 0-21. Historically, an FMS composite score of less than fourteen has been used to predict injury in athletic populations (Mokha et al., 2016). In more recent literature, it was found that asymmetry, or a low FMS component score was a better predictor of injury compared to the FMS composite score (Mokha et al., 2016). Studies also showed the FMS was able to demonstrate differences between injured and uninjured participants in both the FMS component score, as well as the FMS composite score, including the deep squat (Dorrel et al., 2018). Dorrel and colleagues (2018) were also able to demonstrate that the internal consistency among FMS component tests were higher than the FMS composite assessment, concluding that clinicians would be more efficient and attain accurate assessments by executing individual component tests (Dorrel et al., 2018). Dorrell and colleagues (2018) highlighted the previous literature related to the prognostic accuracy of the FMS as having greater than 50\% accuracy of correctly classifying those who were at a greater risk of injury (Dorrel et al., 2018). However, the study Dorrell and colleagues (2018) conducted showed that the FMS was not good at providing discriminatory predictions of musculoskeletal injuries (Dorrel et al., 2018). A prospective cohort study done by Bardenett and colleagues (2015) showed that the FMS was useful for recognizing certain movement faults, but was not useful for overall prediction of injury in high school athletes (Bardenett et al., 2015). While the FMS assesses the quality of motion, Kinovea 2D motion analysis gives precise measurements of specific joint performance (Krause et al., 2015). Kinovea Software is an online free software used for analysis, comparison, and evaluation (Dalal et al., 2018). Kinovea motion analysis also allows for greater objectivity in the assessment of joint mobility (Krause et al., 2015). The software can be utilized by physical therapists, other healthcare professionals, athletes, and coaches (Dalal et al., 2018). The current study population (19- 42 years of age) consisted of participants who were currently experiencing LBP symptoms, while the control group participants were not currently having LBP symptoms. The purpose of this study is to use the deep squat component of the FMS to indicate the participants with LBP based on the FMS score as compared to identifying participants with LBP based on movement faults determined using Kinovea 2D analysis.

\section{Materials and Method}

The study was conducted with a total of 36 participants based on a Priori power analysis to determine study size. The participants were between the ages of 19-42 ( 21 females and 15 males). Inclusion criteria for participants in the experimental study included current and historic episodes of LBP and for the control group they must be currently free from any symptoms of LBP (15 LBP and 


\section{Journal of Exercise Science \& Physiotherapy Vol. 14 No. 2 (July to December) 2018 \\ ISSN: 0973-2020 (Print) $\quad I_{2}$ OR Impact Factor $=6.115$ UGC Approved [no.7485] ISSN: 2454-6089 (Online)}

21 no LBP). Exclusion criteria included subjects who were not in good health, had undergone any orthopedic surgery within the past 6 months, and who participated in a collegiate sport or currently being professionally trained in the squat.

Upon approval of the IRB from the IRB committee at Sacred Heart University, a cross sectional case study was performed by utilizing the deep squat component of the FMS to assess its ability as an indicator to detect a presence of LBP. Data collection was conducted in the Motion Analysis Lab at the College for Health Education at Sacred Heart University in Fairfield, Connecticut. The lab was divided into two sections by a retractable room divider in order to keep the researchers accessing the deep squat blinded while the participant's history \& demographic information was collected. Health history, demographic information, and consent to participate, was collected by two researchers who were not blinded to the condition of low back pain. The same two researchers marked the participants with four reflective biomarkers on their right lower extremity at the following osseous landmarks: greater trochanter, lateral femoral condyle, lateral malleolus, and the base of the fifth metatarsal (Schurr et al., 2017). These landmarks were selected based on a previous study from Schurr et al. (2017). The base of the fifth metatarsal biomarker was added in order to assess the joint angle at the ankle from the sagittal plane. The other biomarkers were placed to measure angles at the knee and hip joints.

Participants then entered the testing room where three blinded researchers instructed them on the FMS squat using the script provided by the FMS Squat Assessment. A photo photographic consent and release form was provided by our principal investigator to three of our participants in order to be utilized and posted within Appendix A, Figure 1.Participants were instructed to stand with their feet shoulder width apart, which was standardized using their acromion distance to determine foot placement. The participants performed three overhead squats in each of the two FMS standardized testing positions; feet flat on the floor and heels raised on FMS board. Afterwards, participants were asked if they had experienced any pain and were instructed not to specify where the pain was to the researchers. According to FMS standard procedure, any participant who experiences pain during the squat should receive an automatic score of 0 . Researchers in this study decided to deviate from this protocol so that all of the participant's squat mechanisms would be scored regardless of pain; raters scored all participants based on squat mechanics. Scores of 3, 2, or 1 were given as per guidelines of the FMS scoring criteria noted in Figure 2. These scores are used to guide interventions and may predict risk for injury (Krause et al., 2015). Examples of the FMS Squat scores listed from a 3 to a 1 , as demonstrated by some of our participants, is included in (Figure 1).

Video analysis was conducted using Sony Vario-Sonnar cameras on Dolica tripod stands measuring 39.5 inches from the ground, and placed 142 inches away from the FMS board, in both the frontal and right sagittal planes. Videos captured the first squat on the floor and the first squat with the participants heels raised on the FMS board. Sagittal plane videos were analyzed using Kinovea software. The landmarks used to measure the angles at the hip knee and ankle were as follows; hip: greater trochanter, FMS bar, and the lateral condyle of the knee; knee: lateral condyle of the knee, greater trochanter, and lateral malleolus; ankle: lateral malleolus, lateral condyle of the knee, and base of the 5th metatarsal. Angles were measured in the starting position and deepest part of the squat to calculate the total arc of motion of each joint.

A statistical analysis was conducted using IBM SPSS Statistics Version 24 software. FMS relation to LBP/ No LBP was analyzed using a Chi Square test. A discriminant analysis was used to compare FMS scores to joint angles. A Pearson correlation was used to compare joint angles to the presence or absence of LBP. A Pearson Correlation was also used to assess the angles on the board versus off the board. 
Journal of Exercise Science \& Physiotherapy Vol. 14 No. 2 (July to December) 2018

ISSN: 0973-2020 (Print) I I OR Impact Factor =6.115 UGC Approved [no.7485] ISSN: 2454-6089 (Online)

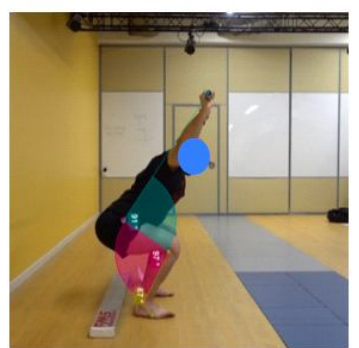

Off Board

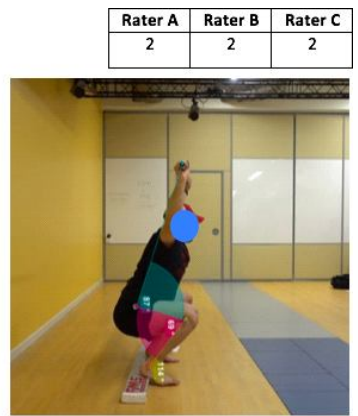

On Board
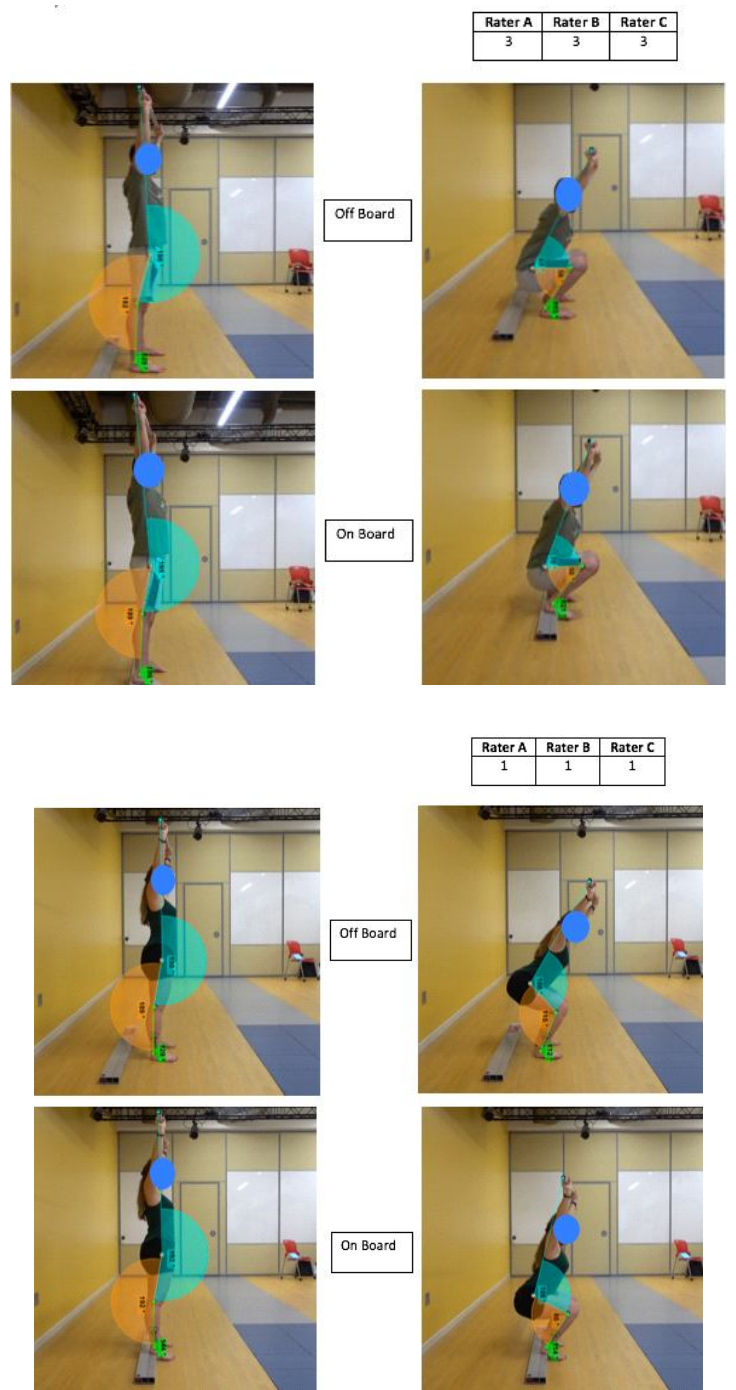

Figure 1: Examples of FMS scores 
Journal of Exercise Science \& Physiotherapy Vol. 14 No. 2 (July to December) 2018

ISSN: 0973-2020 (Print) $\quad I_{2}$ OR Impact Factor $=6.115$ UGC Approved [no.7485] ISSN: 2454-6089 (Online)

\section{Results}

A contingency table and Chi Square $\left(\mathrm{X}^{2}\right)$ test were used to determine if there is an association between FMS score and the presence of LBP (Tables 1a \& 1b). The association was not significant $\left(\mathrm{p}=0.119, \mathrm{df}=2, \mathrm{X}^{2}=4.251\right.$, critical value $\left.=5.99\right)$.

Table 1a. LBP* FMS Crosstabulation

\begin{tabular}{|c|c|c|c|c|c|}
\hline & & & FMS & & \\
\hline LBP & & 1 & 2 & 3 & Total \\
\hline & Count & 7 & 8 & $\overline{0}$ & 15 \\
\hline 1.00 & \% within LBP & $46.7 \%$ & $53 \%$ & $\overline{0 \%}$ & $100 \%$ \\
\hline & \% within FMS & $58.3 \%$ & $40 \%$ & $0 \%$ & $41.7 \%$ \\
\hline & \% of Total & $19.4 \%$ & $22 \%$ & 0\% & $41.7 \%$ \\
\hline & Count & 5 & 12 & 4 & 21 \\
\hline 200 & \% within LBP & $23.8 \%$ & $57 \%$ & $19 \%$ & $100 \%$ \\
\hline & \% within FMS & $41.7 \%$ & $60 \%$ & $100 \%$ & $58.3 \%$ \\
\hline & $\%$ of Total & $13.9 \%$ & $33.3 \%$ & $11.1 \%$ & $58.3 \%$ \\
\hline Total & Count & 12 & 20 & 4 & 36 \\
\hline & \% within LBP & $33.3 \%$ & $55.6 \%$ & $11.1 \%$ & $100 \%$ \\
\hline & \% within FMS & $100 \%$ & $100 \%$ & $100 \%$ & $100 \%$ \\
\hline & $\%$ of Total & $33.3 \%$ & $55.6 \%$ & $11.1 \%$ & $100 \%$ \\
\hline
\end{tabular}

Table 1b: Chi-Square Tests

\begin{tabular}{|l|l|l|l|}
\hline & Value & df & $\begin{array}{l}\text { Asymptotic } \\
\text { Significance (2-sided) }\end{array}$ \\
\hline Pearson Chi-Square & $4^{251} 1^{\mathrm{a}}$ & $\mathbf{2}$ & .119 \\
\hline Likelihood Ratio & $\mathbf{5 . 6 8 1}$ & 2 & .058 \\
\hline Linear-by-Linear Association & 3.781 & 1 & .052 \\
\hline N of Valid Cases & 36 & & \\
\hline $\begin{array}{l}\text { 2 cells (33.3\%) have expected count less than 5. The minimum } \\
\text { expected count is } 1.67\end{array}$ \\
\hline
\end{tabular}

A discriminant analysis was conducted to compare FMS scores and joint angles. The mean associated with each joint angle in relation to FMS scores is presented in Table 2, along with total mean joint angles for all FMS scores combined. The test of equality of group means demonstrates that mean knee joint angles on the ground and on the board are statistically significant for each FMS score $(p<0.05)$, whereas ankle and hip joint angles on the board and the ground wee not (Ankle-Board: $p=0.667$, Ankle-Ground: $p=0.102$, Hip-Board: $p=0.120$, Hip-Ground: $p=0.074$ ). Box's M demonstrates a significant value for equal group variance ( $p>0.001$, Table 3$)$. The canonical correlation is 0.644 , which when squared, shows the effect size of 0.415 . Wilks' lambda was shown to be statistically significant with joint angle variables predicting the outcome of FMS scores at a statistically significant level $(\lambda=0.585, \mathrm{p}<0.05)$. The standardized canonical discriminant function coefficient shows the knee joint angle on the ground as having the highest predictive capability (Function=1.00; Table 4). The results from this analysis demonstrate that joint angles are able to predict FMS scores in $41.7 \%$ of people who would score a 1 on the FMS, predict $80 \%$ of people who would score a 2 and $50 \%$ of the people who would score a 3 .

A Pearson correlation $(\rho)$ was used to compare joint angles to the presence or absence of LBP. Knee joint angle on the board was shown to have a moderate correlation to those with LBP $(\rho=0.520)$. Knee joint angle on the ground was shown to have a moderate correlation to those with $\operatorname{LBP}(\rho=0.461)$. Ankle joint angle on the board had a low correlation to those with LBP $(\rho=0.301)$. 
Journal of Exercise Science \& Physiotherapy Vol. 14 No. 2 (July to December) 2018

ISSN: 0973-2020 (Print) I2OR Impact Factor =6.115 UGC Approved [no.7485] ISSN: 2454-6089 (Online)

Ankle joint angle on the ground had a low correlation to those with LBP $(\rho=0.368)$. Hip joint angle on the board had a very low correlation to those with $\operatorname{LBP}(\rho=0.193)$. Hip joint angle on the ground had a low correlation to those with $\operatorname{LBP}(\rho=0.301)$.

Table 2. Mean associated with each joint angle in relation to FMS scores

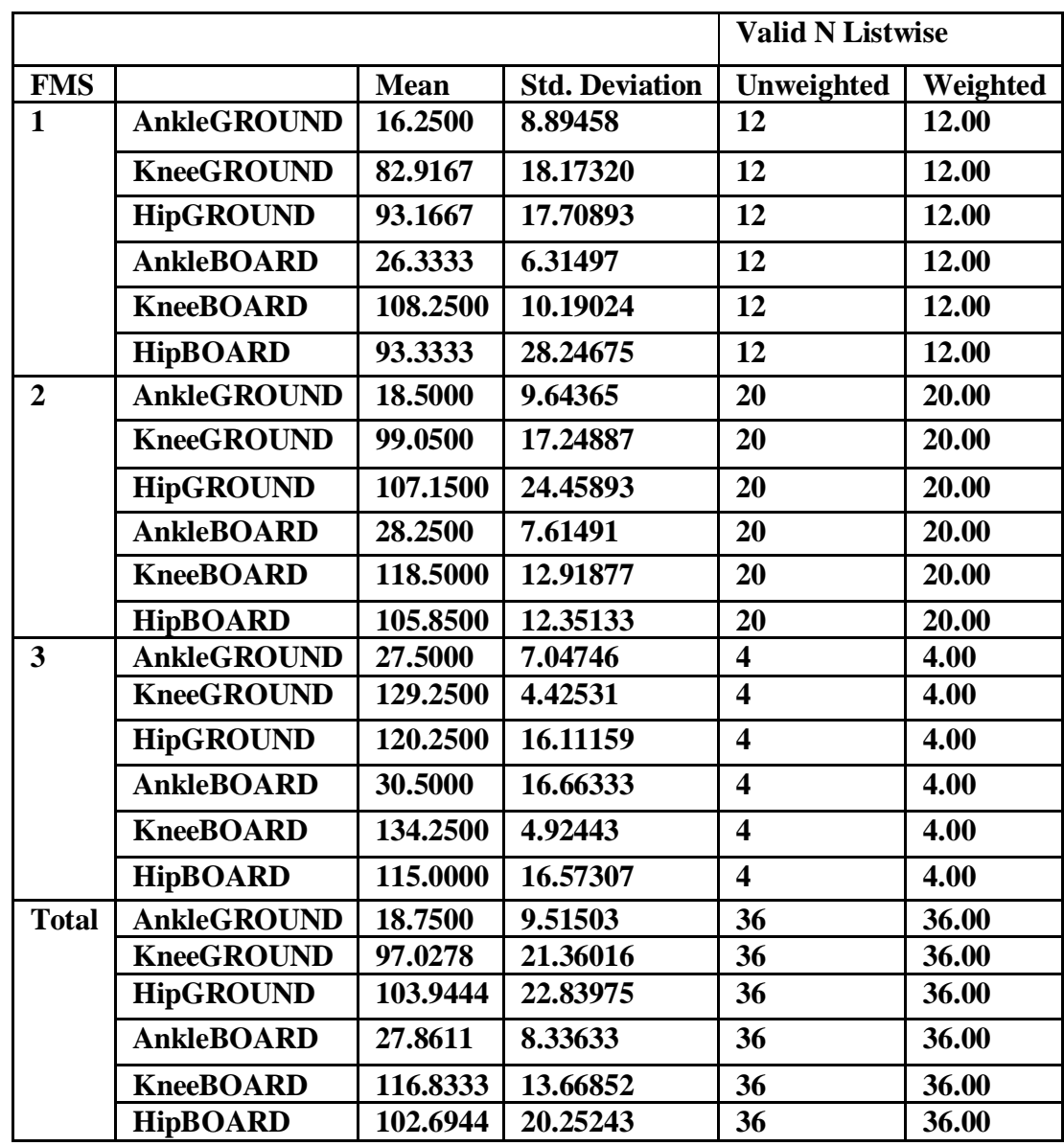

Table 3. Test Results

\begin{tabular}{|lll|}
\hline Box's M & & 5.382 \\
\hline F & Approx. & 2.516 \\
\cline { 2 - 3 } & df1 & 2 \\
\cline { 2 - 3 } & df2 & 722.074 \\
\cline { 2 - 3 } & Sig. & 0.82 \\
$\begin{array}{l}\text { Tests null hypothesis of equal population covariance } \\
\text { matrices. }\end{array}$ & \\
\hline
\end{tabular}


Journal of Exercise Science \& Physiotherapy Vol. 14 No. 2 (July to December) 2018

ISSN: 0973-2020 (Print) $\quad I_{2}$ OR Impact Factor =6.115 UGC Approved [no.7485] ISSN: 2454-6089 (Online)

Table 4. Classification Results ${ }^{\mathrm{a}, \mathrm{c}}$

\begin{tabular}{|c|c|c|c|c|c|c|}
\hline & & & & d Gro & bership & \\
\hline & & FMS & 1.00 & 2.00 & 3.00 & Total \\
\hline Original & Count & 1.00 & 5 & 7 & 0 & 12 \\
\hline & & 2.00 & 3 & 17 & $\mathbf{0}$ & 20 \\
\hline & & 3.00 & $\mathbf{0}$ & 2 & 2 & 4 \\
\hline & $\%$ & 1.00 & 41.7 & 58.3 & .0 & 100.0 \\
\hline & & 2.00 & 15.0 & 85.0 & .0 & 100.0 \\
\hline & & 3.00 & .0 & 50.0 & 50.0 & 100.0 \\
\hline Cross-validated $^{b}$ & Count & 1.00 & 5 & 7 & $\mathbf{0}$ & 12 \\
\hline & & 2.00 & 3 & 16 & 1 & 20 \\
\hline & & 3.00 & $\mathbf{0}$ & 2 & 2 & 4 \\
\hline & $\%$ & 1.00 & 41.7 & 58.3 & .0 & 100.0 \\
\hline & & 2.00 & 15.0 & 80.0 & 5.0 & 100.0 \\
\hline & & 3.00 & .0 & 50.0 & 50.0 & 100.0 \\
\hline $\begin{array}{ll}\text { a. } & 66.7 \% \text { of } \\
\text { b. } & \text { Cross val } \\
\text { the functions derive } \\
\text { c. } \quad 63.9 \% \text { of } \\
\end{array}$ & $\begin{array}{l}\text { ll cases o } \\
\text { lidated g }\end{array}$ & $\begin{array}{l}\text { correct } \\
\text { those c } \\
\text { an that } \\
\text { I cases }\end{array}$ & $\begin{array}{l}\text { sified. } \\
\text { the a } \\
\text { ctly cla }\end{array}$ & $\operatorname{cros}$ & each ca & ssified b \\
\hline
\end{tabular}

A pearson correlation was used to assess the correlation between the angles measured on the board versus on the ground. Knee joint angle on the ground had a moderate correlation with knee joint angle on the board $(\square=0.579)$. Hip joint angle on the ground had a moderate correlation with hip joint angle on the board ( $\square=0.630$ ). Ankle joint angle on the ground had a low correlation with ankle joint angle on the board $(\square=0.224)$.

\section{Discussion}

Our results showed that the FMS was not a good indicator of the presence of LBP and that the deep squat subset should not be used to assess movement faults in those with LBP. Although the FMS scores were not indicative of the presence or absence of LBP, the joint angles collected using 2-D motion capture at the knee were significantly associated with the absence of LBP. An increase in knee joint angles on and off the board are significantly correlated with the absence of LBP. As the knee joint angles on and off the board increased, there was a significant correlation with an increase in FMS scores. No significant correlation was revealed with the ankle or the hip joint angles on or off the board with FMS scores. When comparing the angles on the board to off the board the knee and hip showed a correlation, so that in either the modified or original position the hip and knee had a similar joint arc of motion. The ankle in the original position did not correlate with the modified position as expected because the modified position places the ankle in a greater plantarflexed position. Our study both supports and refutes claims made by others. In the study conducted by Mokha et al. (2016), a cohort study that aimed to determine if a FMS subtest score of 1 would predict musculoskeletal injury in collegiate athletes found the subtests of the FMS were shown to be more predictive of injury. Our study results refute this conclusion because the deep squat subtest was not shown to be predictive of a low back musculoskeletal injury among the population that was tested (Mokha et al., 2016). The study that we conducted also refuted the work done by Dorrel et al., which found that the FMS deep squat portion demonstrated differences in injured versus non injured participants. The data from our participants revealed that the deep squat subtest did not reveal the differences between those with a low back injury as compared to those in good health without low back pain. This study supported the results of Dorrel et al. claiming that the FMS deep squat portion was inaccurate in providing discriminatory predictions of severity in musculoskeletal injury (Dorrel et al., 2018). Discriminating between the type of musculoskeletal injury using the 


\section{Journal of Exercise Science \& Physiotherapy Vol. 14 No. 2 (July to December) 2018 ISSN: 0973-2020 (Print) $\mathrm{I}_{2}$ OR Impact Factor $=6.115$ UGC Approved [no.7485] ISSN: 2454-6089 (Online)}

deep squat is an area for future research. A component of our study can be compared to current research by Krause et al., which supported Kinovea 2-D motion analysis of participant's joint angles when using the FMS deep squat. Evidence from Krause et al., favored 2-D analysis as a close second to the 3-D "gold standard" motion capture for movement assessment. The findings of this study along with our own findings, show that 2-D motion capture is clinically significant when measuring knee joint angles during the deep squat portion of the FMS to screen for low back injury in patients (Krause et al., 2015). The information obtained from conducting this study does not support the use of FMS to screen patients for the presence of low back injury. None of the information gained from the FMS method of scoring helped the raters define the patients who had an injury versus those who did not. Utilizing motion capture analysis in the clinical setting is a beneficial tool that allows objective data collection to reliably define movement faults in symptomatic patients. These tools are often not used due to lengthy set up, cost, and availability in the practice settings. Our suggestion to clinicians is to incorporate 2-D motion capture whenever possible during the screening process. This will not only help define movement faults that are not easily seen through observation assessments, but allows for objective data to be collected in order to show progress throughout treatment in a functional way. The results collected from this study also suggest that knee joint angles during an overhead deep squat is most indicative of low back injury in participants. This being said, clinicians should pay closer attention to these angles during functional squat movements and if using motion capture, this is the most beneficial angle to use for progress measures and tracking purposes throughout the course of treatment. One limitation in the study was a lack of sub grouped participants based on the severity of their LBP. The study also lacked a baseline criteria for the severity of LBP. Additionally, the mechanism of LBP was not taken into account; low back pain caused by a traumatic injury compared to LBP caused from movement faults could yield different results in a motion analysis. The video motion analysis was analyzed from one sagittal view, therefore it was unable to assess for limb asymmetries. Lastly, participants were not measured prior to the assessment for their available joint motion which could affect the Kinovea joint angle analysis. Future research should assess different components of the FMS individually, and the FMS as a whole, in relation to predicting LBP since the deep squat subtest cannot be used in isolation. Research can also look at different squat variations to predicting back injuries such as the back squat or front squat which could show different results due to center of mass changes. Patients with LBP should also be sub-classified based on severity and mechanism of injury. Lastly, others can look at asymmetries that may exist when comparing angles of two sagittal views.

\section{Conclusion}

In conclusion, our study showed that the FMS deep squat screen was not a reliable indicator of patients with low back pain. However, the study results did support the use of Kinovea motion analysis as a reliable objective screening tool. The most reliable objective measure to focus on throughout the Kinovea motion capture was found to be the knee angle during the deep squat motion. Those with a presence of LBP were found to have decreased knee arc of motion, providing clinicians with a movement fault to address in order to prevent further injury.

\section{References}

Ahmed, A., Waqas, M., Ijaz, M., Adeel, M., Haider, R., \& Ahmed, M. (2017). Effectiveness of Core Muscle Stabilization Exercises with and without Lumbar Stretching in Non- Specific Low Back Pain. Annals, 23(3), 347-351.

Bardenett, S. M., Micca, J. J., DeNoyelles, J. T., Miller, S. D., Jenk, D. T., \& Brooks, G. S. (2015). Functional Movement Screen Normative Values And Validity In High School Athletes: Can The Fmstm Be Used As A Predictor Of Injury? International Journal of Sports Physical Therapy, 10(3), 303-308. 


\section{Journal of Exercise Science \& Physiotherapy Vol. 14 No. 2 (July to December) 2018 ISSN: 0973-2020 (Print) $\mathrm{I}_{2}$ OR Impact Factor $=6.115$ UGC Approved [no.7485] ISSN: 2454-6089 (Online)}

Butler, R. J., Plisky, P. J., Southers, C., Scoma, C., \& Kiesel, K. B. (2010). Biomechanical analysis of the different classifications of the Functional Movement Screen deep squat test. Sports Biomechanics, 9(4), $270-279$. https://doi.org/10.1080/14763141.2010.539623

Chenot, J.-F., Greitemann, B., Kladny, B., Petzke, F., Pfingsten, M., \& Schorr, S. G. (2017). Non-Specific Low Back Pain. Deutsches Aerzteblatt Online. https://doi.org/10.3238/arztebl.2017.0883

Childs, J. D., Fritz, J. M., Wu, S. S., Flynn, T. W., Wainner, R. S., Robertson, E. K., ... \& George, S. Z. (2015). Implications of early and guideline adherent physical therapy for low back pain on utilization and costs. BMC Health Services Research, 15(1), 150.

Chu, L. F., D’Arcy, N., Brady, C., Zamora, A. K., Young, C. A., Kim, J. E., ... Clark, D. J. (2012). Analgesic tolerance without demonstrable opioid-induced hyperalgesia: A double-blinded, randomized, placebocontrolled trial of sustained-release morphine for treatment of chronic nonradicular low-back pain: Pain, 153(8), 1583-1592.

Dagenais, S., Caro, J., \& Haldeman, S. (2008). A systematic review of low back pain cost of illness studies in the United States and internationally. The Spine Journal, 8(1), 8-20. https://doi.org/10.1016/j.spinee.2007.10.005

Dalal, K. K., Joshua, A. M., Nayak, A., Mithra, P., Misri, Z., \& Unnikrishnan, B. (2018). Effectiveness of prowling with proprioceptive training on knee hyperextension among stroke subjects using videographic observation- a randomised controlled trial. Gait \& Posture, 61, 232-237.

Dorrel, B., Long, T., Shaffer, S., \& Myer, G. D. (2018). The Functional Movement Screen as a Predictor of Injury in National Collegiate Athletic Association Division II Athletes. Journal of Athletic Training, 53(1), 29-34.

Frogner, B. K., Harwood, K., Andrilla, C. H., Schwartz, M., \& Pines, J. M. (2018). Physical Therapy as the First Point of Care to Treat Low Back Pain: An Instrumental Variables Approach to Estimate Impact on Opioid Prescription, Health Care Utilization, and Costs. Health Services Research.

Gore, M., Sadosky, A., Stacey, B. R., Tai, K. S., \& Leslie, D. (2012). The burden of chronic low back pain: clinical comorbidities, treatment patterns, and health care costs in usual care settings. Spine, 37(11), E668-E677.

Hoy, D., Bain, C., Williams, G., March, L., Brooks, P., Blyth, F., ... Buchbinder, R. (2012). A systematic review of the global prevalence of low back pain. Arthritis \& Rheumatism, 64(6), 2028-2037.

Krause, D. A., Boyd, M. S., Hager, A. N., Smoyer, E. C., Thompson, A. T., \& Hollman, J. H. (2015). Reliability And Accuracy Of A Goniometer Mobile Device Application For Video Measurement Of The Functional Movement Screen Deep Squat Test. International Journal of Sports Physical Therapy, 10(1), 37-44.

Meucci, R. D., Fassa, A. G., Paniz, V. M., Silva, M. C., \& Wegman, D. H. (2013). Increase of chronic low back pain prevalence in a medium-sized city of southern Brazil. BMC Musculoskeletal Disorders, 14(1).

Mokha, M., Sprague, P. A., \& Gatens, D. R. (2016). Predicting Musculoskeletal Injury in National Collegiate Athletic Association Division II Athletes From Asymmetries and Individual-Test Versus Composite Functional Movement Screen Scores. Journal of Athletic Training, 51(4), 276-282.

Myer, G. D., Kushner, A. M., Brent, J. L., Schoenfeld, B. J., Hugentobler, J., Lloyd, R. S., ... McGill, S. M. (2014). The back squat: A proposed assessment of functional deficits and technical factors that limit performance. Strength and Conditioning Journal, 36(6), 4-27. https://doi.org/10.1519/SSC.0000000000000103

Searle, A., Spink, M., Ho, A., \& Chuter, V. (2015). Exercise interventions for the treatment of chronic low back pain: a systematic review and meta-analysis of randomised controlled trials. Clinical rehabilitation, 29(12), 1155-1167.

Schurr, S. A., Marshall, A. N., Resch, J. E., \& Saliba, S. A. (2017). Two-Dimensional Video Analysis is Comparable to 3D Motion Capture in Lower Extremity Movement Assessment. International Journal of Sports Physical Therapy, 12(2), 163-172.

Shultz, R., Anderson, S. C., Matheson, G. O., Marcello, B., \& Besier, T. (2013). Test-Retest and Interrater Reliability of the Functional Movement Screen. Journal of Athletic Training, 48(3), 331-336. https://doi.org/10.4085/1062-6050-48.2.11

Zheng, P., Kao, M. C., Karayannis, N. V., \& Smuck, M. (2017). Stagnant physical therapy referral rates alongside rising opioid prescription rates in patients with low back pain in the United States 1997-2010. Spine, 42(9), 670-674.

Conflict of Interest: None declared 